\title{
Persebaran Layanan dan Infrastruktur Telekomunikasi Provinsi Papua
}

\author{
Prajna Deshanta Ibnugraha ${ }^{1}$, Tora Fahrudin ${ }^{2}$ \\ ${ }^{1,2}$ Fakultas Ilmu Terapan Universitas Telkom \\ Jl Telekomunikasi Terusan Buah Batu Bandung 40257 \\ 1 prajna@tass.telkomuniversity.ac.id, ${ }^{2}$ torafahrudin@tass.telkomuniversity.ac.id
}

\begin{abstract}
Abstrak — Layanan dan infrastruktur telekomunikasi merupakan bagian penting dari kehidupan modern karena hampir di segala bidang membutuhkan hal tersebut seperti pendidikan, pemerintahan, ekonomi dan sebagainya. Oleh karena pentingnya sektor telekomunikasi di Indonesia sebagai negara kepulauan maka perlu evaluasi tentang penyebaran layanan dan infrastrukturnya selain dilihat dari sisi fungsional dan perkembangan teknologinya. Provinsi Papua adalah provinsi terbesar di Indonesia namun justru memiliki layanan telekomunikasi yang paling sedikit dan terbatas. Demikian pula untuk penyebaran layanan ke kabupaten maupun ke distrik (kecamatan) masih belum merata. Hal tersebut terbukti dari laporan hasil distribusi pita frekuensi yang hanya 1,5\% untuk kawasan Maluku dan Papua serta kerapatan layanan tiap kabupaten yang ditunjukkan pada hasil penelitian ini.
\end{abstract}

Kata kunci : penyebaran; telekomunikasil, papua

Abstract - Services and telecommunications infrastructure is an important part of modern life such as education, government, economics and so on. Hence the importance of the telecommunications sector in Indonesia as an archipelagic country is necessary to evaluate the spread of services and infrastructure apart in terms of functional and technological developments. Papua Province is the largest province in Indonesia, but it has the least amount of telecommunications services. The deployment of service to the district and to the sub district is still not evenly distributed. This report results prove that distribution of the frequency band which is only $1.5 \%$ for the region as well as Maluku and Papua density of each district services shown in the results of this study.

Keywords : spread; telecommunication; papua

\section{PENDAHULUAN}

Provinsi Papua memiliki luas 309.934,4 km2 yang terbagi menjadi 28 kabupaten dan 1 kota dengan jumlah kecamatan / distrik sebanyak 385 distrik dan total desa sebanyak 3.565 desa [1]. Berikut data distrik dan desa per kabupaten di Provinsi Papua

Berdasarkan sensus penduduk tahun 2010, jumlah penduduk Provinsi Papua adalah 2.833.381 [4] yang terdiri dari $52,47 \%$ berjenis kelamin laki-laki dan $47,53 \%$ berjenis kelamin perempuan [2]. Pertambahan jumlah penduduk di Provinsi Papua dari tahun 2000* sampai tahun 2010 adalah sekitar 27,57 $\%$, yaitu dari 2.220.934 jiwa ke 2.833.381 jiwa [2]. Seiring dengan pertumbuhan penduduk tersebut, kualitas manusia di Provinsi Papua juga meningkat. Khusus untuk Provinsi Papua, peningkatan Indeks Pembangunan Manusia rentang tahun 2008-2010 adalah sebesar 0,94 [2].

Tabel 1. Peningkatan indeks pembangunan manusia provinsi Papua (2008 s/d 2010) [2]

\begin{tabular}{cc}
\hline $\begin{array}{c}\text { Rentang } \\
\text { Tahun }\end{array}$ & $\begin{array}{c}\text { Peningkatan Indeks Pembangunan } \\
\text { Manusia }\end{array}$ \\
\hline $2008-2009$ & 0,53 \\
$2009-2010$ & 0,41
\end{tabular}

\begin{tabular}{cc}
\hline $\begin{array}{c}\text { Rentang } \\
\text { Tahun }\end{array}$ & $\begin{array}{c}\text { Peningkatan Indeks Pembangunan } \\
\text { Manusia }\end{array}$ \\
\hline $2008-2010$ & 0,94 \\
\hline
\end{tabular}

Sedangkan tingkat kemiskinan masyarakat Provinsi Papua dari tahun 2009-2012 menurun. Hal tersebut dapat dilihat dari prosentase penduduk miskin di Provinsi Papua :

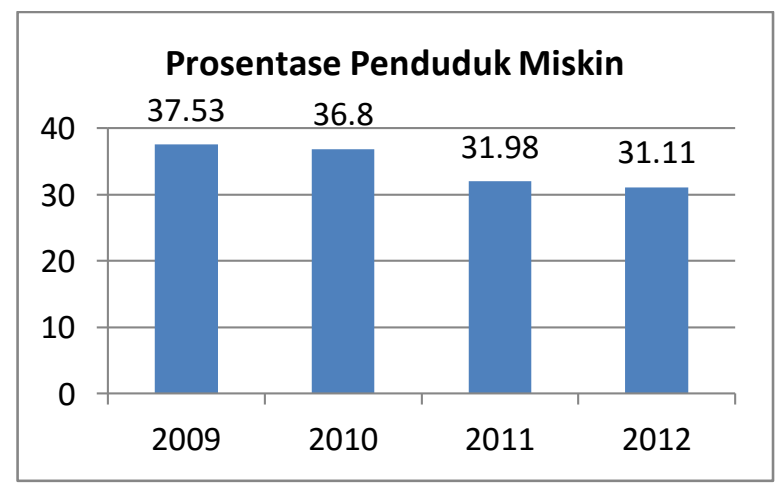

Gambar 1. Prosentase penduduk miskin di Provinsi Papua (2009-2012) [3]

Pada rentang tahun 2009-2010 terjadi penurunan sebesar $0,73 \%$, pada rentang tahun 2010-2011 terjadi penurunan sebesar $4,82 \%$ dan pada rentang tahun 
2011-2012 terjadi penurunan sebesar 0,87 \%. Jadi total penurunan prosentase penduduk miskin di Provinsi Papua dari tahun 2009 sampai dengan tahun 2012 adalah sebesar 6,42\%.

Tabel 2. Penurunan prosentase penduduk miskin 2009 s/d 2012

\begin{tabular}{cc}
\hline Rentang Tahun & $\begin{array}{c}\text { Penurunan Prosentase } \\
\text { Penduduk Miskin }\end{array}$ \\
\hline $2009-2010$ & $0.73 \%$ \\
$2010-2011$ & $4.82 \%$ \\
$2011-2012$ & $0.87 \%$ \\
$2009-2012$ & $6,42 \%$ \\
\hline
\end{tabular}

Namun pada tahun 2013, jumlah penduduk miskin di Provinsi Papua adalah 31,53\% [3]. Jika dibandingkan dengan tahun 2012, jumlah penduduk miskin di Provinsi Papua mengalami kenaikan sebesar 0,42\%.

Keterangan : * kondisi belum ada Provinsi Papua

\section{PROFIL LAYANAN TELEKOMUNIKASI DI PRIVINSI PAPUA}

Provinsi Papua memiliki wilayah terluas

dibandingkan dengan seluruh provinsi di Indonesia.

Tabel 3. Penggunaan pita frekuensi per propinsi semester 1-2013 [4]

\begin{tabular}{|c|c|c|c|c|c|c|}
\hline \multirow[b]{2}{*}{ No. } & \multirow{2}{*}{ Propinsi } & \multicolumn{5}{|c|}{ Pita Frekuensi } \\
\hline & & MF & HF & VHF & UHF & SHF \\
\hline 1 & NAD & 10 & 81 & 5,822 & 2,364 & 767 \\
\hline 2 & Sumatera Utara & 29 & 277 & 18,059 & 6,434 & 1,702 \\
\hline 3 & Sumatera Barat & 11 & 50 & 6,498 & 2,313 & 496 \\
\hline 4 & Riau & 3 & 236 & 11,932 & 4,847 & 1,236 \\
\hline 5 & Jambi & 4 & 120 & 4,838 & 1,321 & 671 \\
\hline 6 & Sumatera Selatan & 10 & 116 & 9,925 & 2,949 & 1,600 \\
\hline 7 & Bengkulu & 2 & 42 & 2,011 & 589 & 219 \\
\hline 8 & Lampung & 9 & 38 & 8,322 & 3,035 & 465 \\
\hline 9 & Kepulauan Riau & 1 & 49 & 4,311 & 1,747 & 650 \\
\hline 10 & Bangka Belitung & 0 & 54 & 2,895 & 711 & 253 \\
\hline 11 & Banten & 3 & 30 & 13,929 & 4,863 & 352 \\
\hline 12 & DKI Jakarta & 8 & 319 & 21,860 & 10,254 & 583 \\
\hline 13 & Jawa Barat & 41 & 132 & 46,004 & 15,756 & 1,412 \\
\hline 14 & Jawa Tengah & 44 & 83 & 26,852 & 10,097 & 1,161 \\
\hline 15 & DI Yogyakarta & & 12 & 5,534 & 2,162 & 400 \\
\hline 16 & Jawa Timur & 25 & 207 & 29,313 & 13,892 & 1,289 \\
\hline 17 & Bali & 8 & 69 & 7,417 & 3,021 & 609 \\
\hline 18 & NTB & 4 & 77 & 4,651 & 1,798 & 679 \\
\hline 19 & NTT & 2 & 286 & 2,326 & 762 & 686 \\
\hline 20 & Kalimantan Selatan & 4 & 72 & 5,346 & 1,584 & 1,708 \\
\hline 21 & Kalimantan Barat & 14 & 210 & 6,418 & 1,812 & 561 \\
\hline 22 & Kalimantan Timur & 3 & 399 & 8,305 & 3,332 & 2,662 \\
\hline 23 & Kalimantan Tengah & 9 & 245 & 3,488 & 1,261 & 747 \\
\hline 24 & Sulawesi Selatan & 14 & 109 & 9,244 & 3,023 & 591 \\
\hline 25 & Sulawesi Tenggara & 0 & 39 & 1,915 & 599 & 348 \\
\hline 26 & Sulawesi Tengah & 6 & 118 & 2,470 & 702 & 380 \\
\hline 27 & Sulawesi Barat & 1 & 20 & 333 & 111 & 13 \\
\hline 28 & Sulawesi Utara & 1 & 94 & 3,299 & 1,153 & 328 \\
\hline 29 & Gorontalo & 0 & 40 & 946 & 176 & 55 \\
\hline 30 & Maluku & 1 & 302 & 720 & 294 & 439 \\
\hline 31 & Maluku Utara & 0 & 122 & 317 & 89 & 179 \\
\hline 32 & Papua & 6 & 1228 & 732 & 582 & 0 \\
\hline 33 & Papua Barat & 0 & 344 & 380 & 163 & 233 \\
\hline
\end{tabular}

Namun Provinsi Papua memiliki distribusi penggunaan pita frekuensi paling kecil. Hal tersebut dapat ditunjukkan pada data statistik berikut :

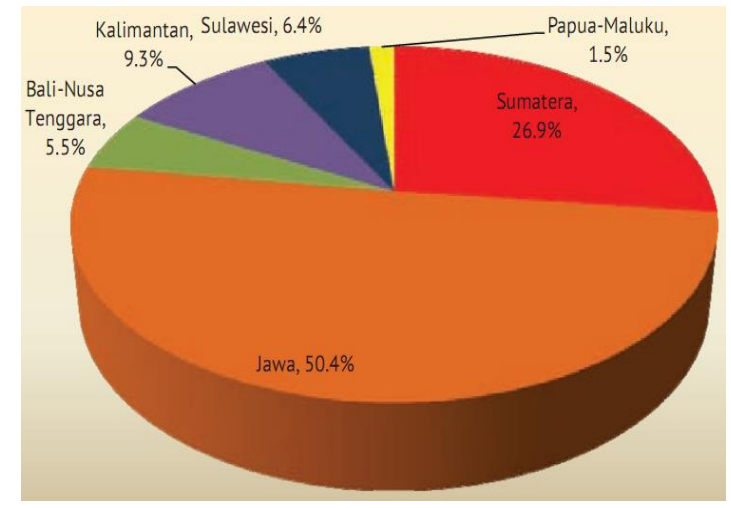

Gambar 2. Distribusi penggunaan pita spektrum menurut pulau besar semester 1-2013 [4]

Dengan jumlah penggunaan pita frekuensi dapat di lihat pada Tabel 3 . 


\section{METODOLOGI DAN PEMBAHASAN}

Metodologi penelitian ini menggunakan pendekatan :

a. Pencarian referensi statistik

b. Menyiapkan form survey langsung

c. Menganalisa hasil dari survey langsung dan menyajikan dalam bentuk grafik

Pada tahap pembahasan, data yang disajikan merupakan data kuantitatif yang didapatkan dalam proses survei (pendataan langsung).

\section{A. Penyebaran Infrastruktur Telekomunikasi Berdasarkan Jenis Layanan}

Dengan mengadakan survey langsung, maka persebaran jumlah infrastruktur layanan telekomunikasi didaerah papua dapat dilihat dalam bentuk Tabel 4 dan Gambar 3.

Tabel 4. Jumlah infrastruktur telekomunikasi berdasarkan jenis layanan

\begin{tabular}{cccc}
\hline No & Jenis Layanan & $\begin{array}{c}\text { Jumlah } \\
\text { Infrastruktur }\end{array}$ & Prosentase \\
\hline 1 & Seluler & 192 & $46,38 \%$ \\
2 & Internet & 64 & $15,46 \%$ \\
3 & Radio & 43 & $10,39 \%$ \\
4 & VSAT & 43 & $10,14 \%$ \\
5 & Televisi & 40 & $9,66 \%$ \\
6 & SSB & 33 & $7,97 \%$ \\
& Total & 414 & $100,00 \%$ \\
\hline
\end{tabular}

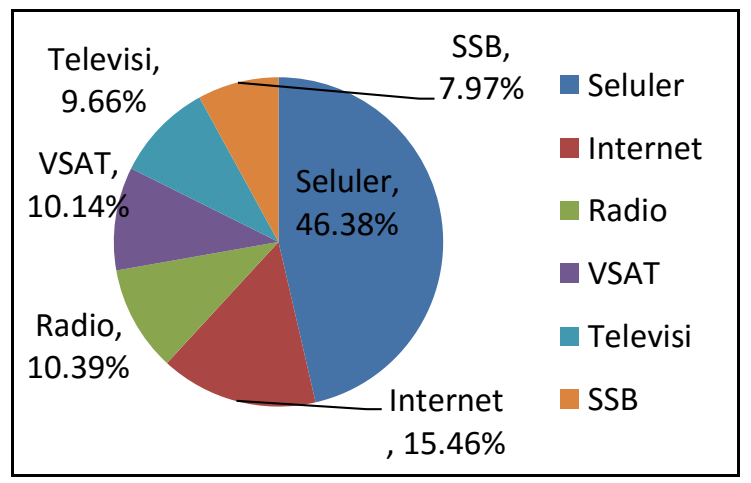

Gambar 3. Grafik kuantitas infrastruktur telekomunikasi di Provinsi Papua

Infrastruktur telekomunikasi telepon seluler berupa BTS memiliki kuantitas paling banyak dibandingkan dengan jenis layanan telekomunikasi yang lain, yaitu sebesar 46,38 \%. Sedangkan layanan telekomunikasi radio SSB memiliki infrastruktur yang paling sedikit, yaitu sekitar 7,97\%.

Berdasarkan status kepemilikan infrastruktur radio yang berada di Provinsi Papua 51,16\% stasiun radio adalah milik pemerintah sedangkan sisanya $48,84 \%$ stasiun radio adalah milik swasta.

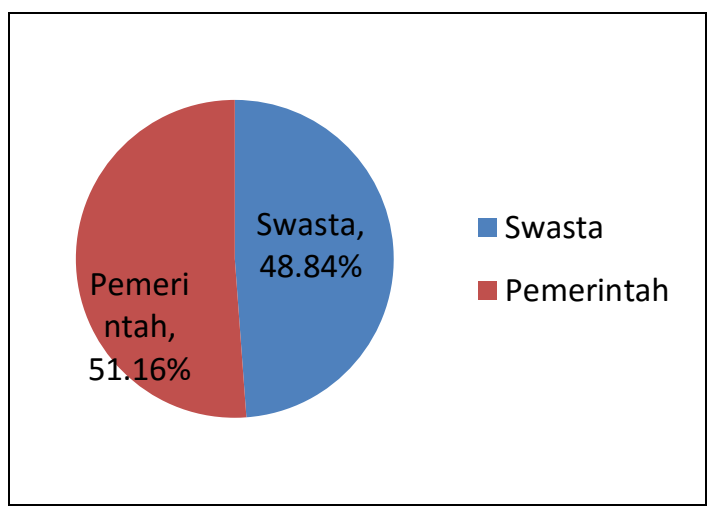

Gambar 4. Grafik kepemilikan stasiun radio

Untuk status pengelola infrastruktur televisi berupa stasiun pemancar televisi yang berada di Provinsi Papua, 60\% pemancar dikelola oleh pemerintah sedangkan sisanya $40 \%$ pemancar dikelola oleh pihak swasta.

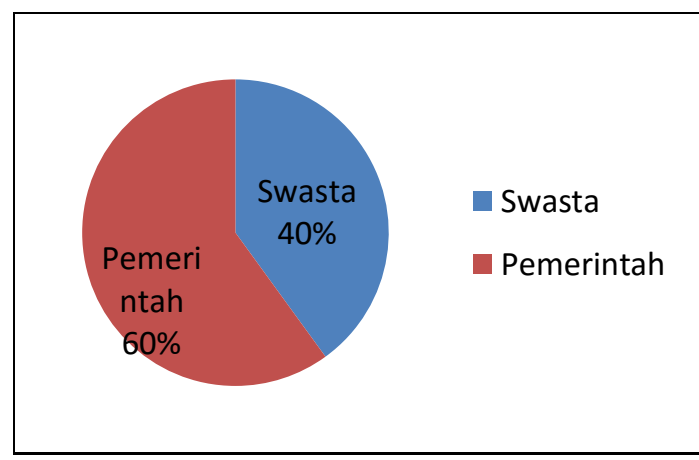

Gambar 5. Grafik kepemilikan infrastruktur televisi berupa pemancar

Berdasarkan kepemilikan infrastruktur layanan telepon seluler berupa BTS, PT. Telkomsel memiliki infrastruktur paling banyak dibandingkan operator lain, yaitu sebesar 70,31\%. Kemudian disusul PT. Indosat 26,04\%, PT. XL Axiata 2,08\% dan sisanya adalah operator lain. Untuk infrastruktur layanan internet, 40,63 layanan dikelola oleh pemerintah sedangkan 59,38\% dikelola oleh pihak swasta.

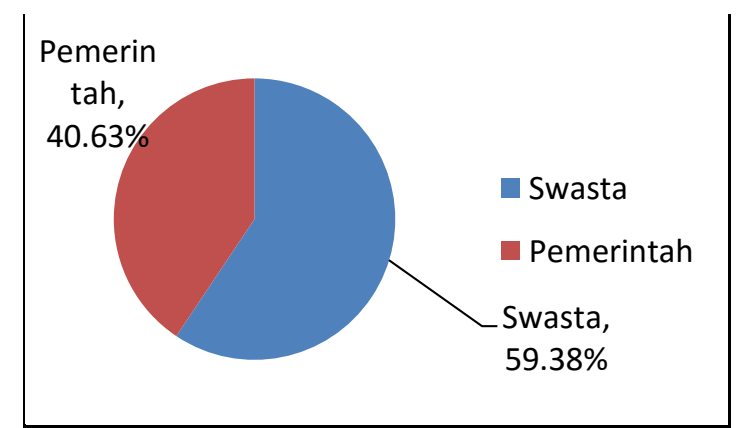

Gambar 6. Grafik kuantitas pengelola layanan internet di Provinsi Papua 
B. Penyebaran Infrastruktur Telekomunikasi Berdasarkan Wilayah

- Radio

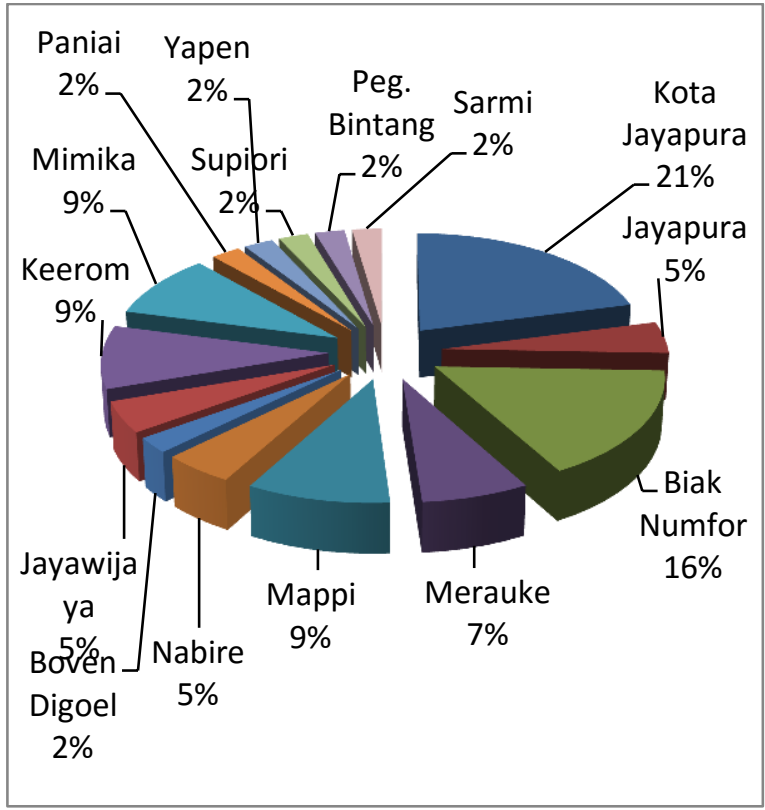

Gambar 7. Grafik penyebaran infrastruktur radio per kabupaten

Kota Jayapura memiliki jumlah infrastruktur radio paling banyak, yaitu sekitar 20,93\% yang kemudian disusul oleh Kabupaten Biak Numfor $(16,28 \%)$.

- Televisi

Untuk prosentase keberadaan infrastruktur layanan televisi paling banyak adalah di Kota Jayapura (30 \%), kemudian disusul oleh Kabupaten Supiori sebesar $20 \%$.

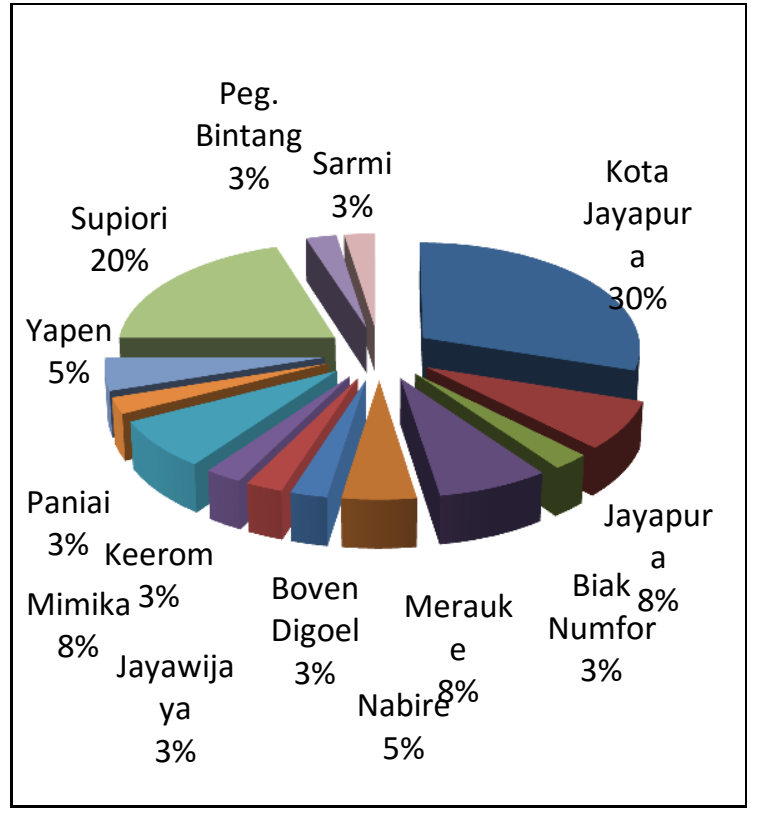

Gambar 8. Grafik penyebaran infrastruktur televisi per kabupaten
- VSAT

Untuk prosentase keberadaan infrastruktur VSAT paling banyak adalah di Kabupaten Pegunungan Mappi, yaitu sebesar $38 \%$. Kemudian disusul dengan Kabupaten Pegunungan Bintang (24\%) dan Kabupaten Keerom (14\%).

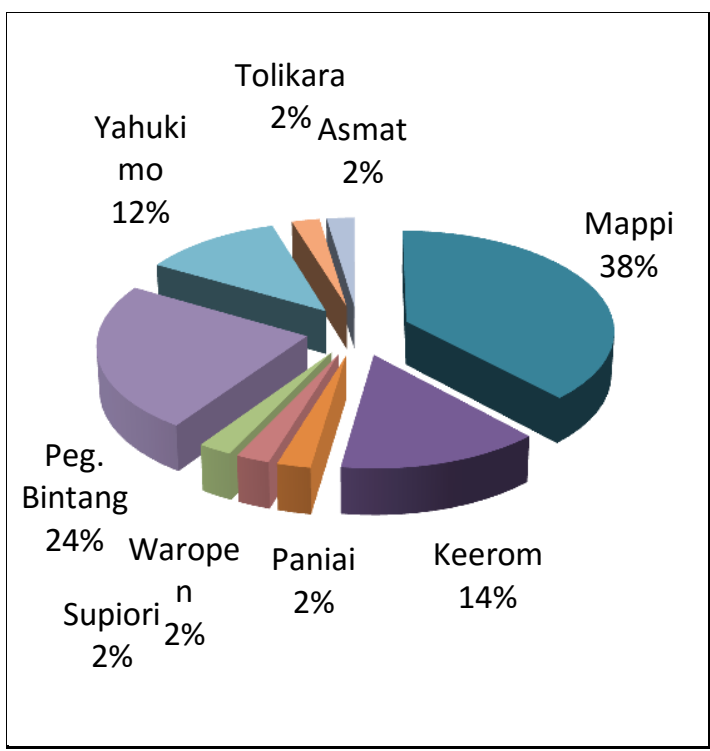

Gambar 9. Grafik penyebaran infrastruktur VSAT per kabupaten

- Layanan Internet

Untuk penyelenggara layanan internet paling banyak berada di Kabupaten Merauke (58\%) kemudian disusul dengan Kabupaten Keerom (33\%), Kabupaten Tolikara (8\%), Kabupaten Pegunungan Bintang (2\%). Berdasarkan data yang didapat dalam kegiatan ini, kabupaten lainnya tidak memiliki perangkat internet.

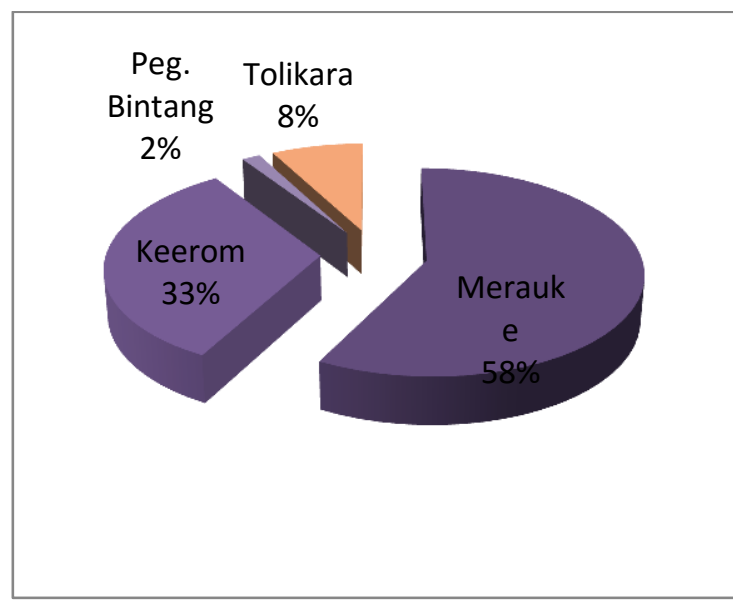

Gambar 10. Grafik penyebaran infrastruktur internet per kabupaten 
- Telepon Seluler

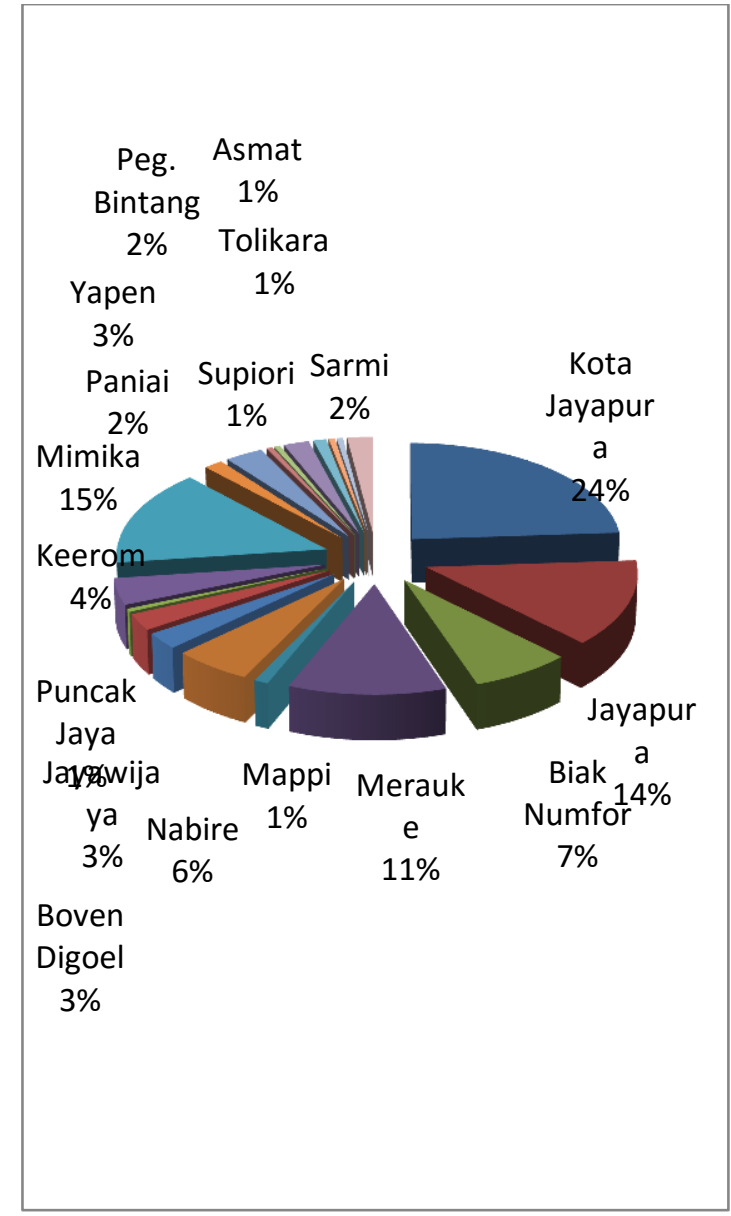

Gambar 11. Grafik penyebaran infrastruktur seluler per kabupaten

- Radio

Untuk keberadaan infrastruktur radio SSB, Kabupaten Sarmi memiliki jumlah paling besar, yaitu $30 \%$ dari jumlah keseluruhan infrastruktur radio SSB yang terdata pada kegiatan ini. Kemudian disusul oleh Kabupaten Pegunungan Bintang sebesar $15 \%$.

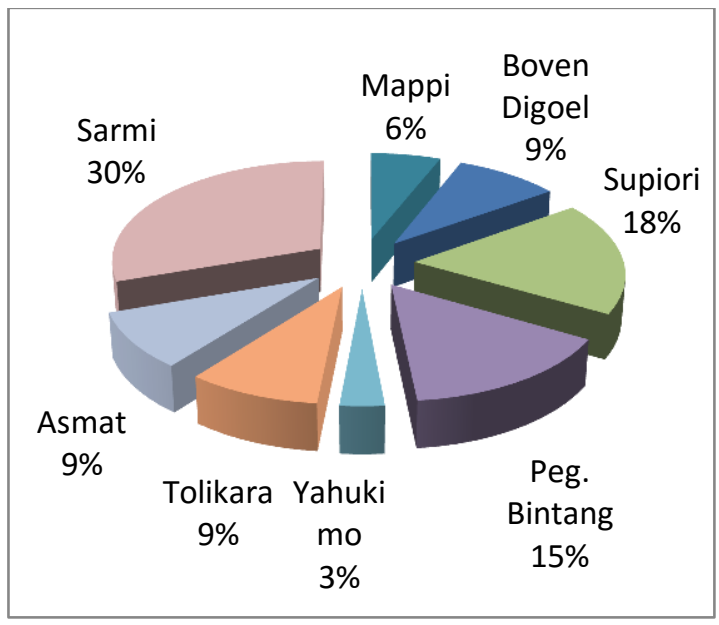

Gambar 12. Grafik penyebaran infrastruktur radion SSB

\section{PENUTUP}

Dari penguraian data berdasarkan hasil survey di atas, didapat beberapa kesimpulan dan saran sebagai berikut:

\section{A. Kesimpulan}

1. Berdasarkan data, Indeks Pembangunan Manusia di Provinsi Papua meningkat setiap tahun namun tidak disertai dengan peningkatan jumlah fasilitas telekomunikasi yang memadai pula.

2. Penyebaran layanan telekomunikasi di Provinsi Papua masih belum merata. Hal tersebut ditunjukkan dari prosentase jumlah layanan dan infrastruktur telekomunikasi yang penyebarannya terpusat di wilayah tertentu seperti Jayapura.

\section{B. Saran}

1. Peningkatan Indeks Pembangunan Manusia harus didukung dengan fasilitas telekomunikasi untuk mengejar ketertinggalan dengan daerah lain.

2. Penyebaran layanan telekomunikasi harus dilakukan oleh pemerintah yang didukung oleh swasta namun memerlukan perancangan dan implementasi yang tepat sehingga pemanfaatannya dapat optimal.

\section{DAFTAR PUSTAKA}

[1] http://id.wikipedia.org/wiki/Daftar_provinsi_di_Indone sia

[2] BPS Provinsi Papua. 1996-2012. http://www.bps.go.id/tab_sub/view.php?kat=1\&tabel= $1 \&$ daftar=1\&id_subyek=26\&notab=2. (diakses tanggal 01 Maret 2014 pukul 20:00)

[3] BPS Provinsi Papua. 2009-2013. Data Statistik: Jumlah dan Persentase Penduduk Miskin, Garis Kemiskinan, Indeks Kedalaman Kemiskinan (P1), dan Indeks Keparahan Kemiskinan (P2) Menurut Provinsi. http://www.bps.go.id/tab_sub/view.php?kat=1\&tabel= $1 \&$ daftar $=1 \&$ id_subyek=23\&notab=2 (diakses tanggal 01 Maret 2014 pukul 20:00)

[4] BPS-RI. 2010. Penduduk Indonesia menurut Provinsi 1971, 1980, 1990, 1995, 2000 dan 2010. http://www.bps.go.id/tab_sub/view.php?kat=1\&tabel= $1 \&$ daftar $=1 \&$ id subyek $=12 \&$ notab $=1$. . (diakses tanggal 01 Maret 2014 pukul 20:00) 
